\title{
Phosphatidylinositol Transfer Protein Expression Altered by Aging and Parkinson Disease
}

\author{
Małgorzata Chalimoniuk, ${ }^{1,4}$ Gerry T. Snoek, ${ }^{2}$ Agata Adamczyk, ${ }^{1}$ \\ Andrzej Małecki, ${ }^{3}$ and Joanna B. Strosznajder ${ }^{1}$
}

Received October 17, 2005; accepted April 24, 2006; Published online: June 16, 2006

\begin{abstract}
SUMMARY
1. Phosphatidylinositol transfer proteins (PI-TP) are responsible for the transport of phosphatidylinositol (PI) and other phospholipids from endoplasmic reticulum to the other membranes and indirectly for lipid mediated signaling. Till now little is known about PITPs in brain aging and neurodegeneration. The aim of this study was to investigate expression of PI-TP in the brain during aging and in animal's model of Parkinson disease (PD) induced by 1-methyl-4-phenyl-1,2,3,6-tetrahydropyridine (MPTP). Moreover, in vitro, effect of 1-methyl-4-phenyl-pyridine cation $\left(\mathrm{MPP}^{+}\right)$on PI-TP, tyrosine hydroxylase $(\mathrm{TH})$ protein level, and viability of cells was investigated.

2. Wistar rats 4, 24, and 36 months old and C57/BL mice and rat pheochromocytoma (PC12) cell line were used for the studies. Mice C57/BL received three injections of MPTP in saline at $2 \mathrm{~h}$ intervals in a total dose of $40 \mathrm{mg} / \mathrm{kg}$ and then after 3,7 , and 14 days they were used for the investigation. PC12 cells were treated with increasing concentration (50$300 \mu \mathrm{M}$ ) of $\mathrm{MPP}^{+}$for $24 \mathrm{~h}$ at $37^{\circ} \mathrm{C}$. The level of $\mathrm{PI}^{-\mathrm{TP}_{\alpha} \text { and } \beta}$ and $\mathrm{TH}$ were determined using Western Blot analysis.

3. Our data indicated that PI-TP $\mathrm{TP}_{\alpha}$ and level decreased in brain of 36 months old rat by $20 \%$ comparing to the control value ( 4 months old). In animal's model of PD, PI$\mathrm{TP}_{\alpha}$ and $\beta$ level was significantly lower by $85,69,64 \%$ in striatum at 3,7 , and 14 days after MPTP injection, respectively, compared to the control value. $\mathrm{MPP}^{+}$decreased PI$\mathrm{TP}_{\alpha}$ and $\beta$, TH expression, and viability of PC12 cells in a dose-dependent manner. $\mathrm{H}_{2} \mathrm{O}_{2}$, menadione, and NO donor significantly decreased the PI-TP level and viability of PC12 cells.

4. Our results indicate the lower protein expression of $\mathrm{PI}-\mathrm{TP}_{\alpha}$ and $\beta$ in aged brain and in PD and suggest that oxidative stress may be responsible for the alteration of PI-TP.
\end{abstract}

KEY WORDS: Phosphatidylinositol transfer protein; Aging; Parkinson disease; Neurodegeneration; Oxidative stress.

\footnotetext{
${ }^{1}$ Medical Research Center, Department of Cellular Signaling, Polish Academy of Sciences, Warsaw, Poland.

${ }^{2}$ Centre for Biomembranes and Lipid Enzymology, Utrecht, The Netherlands.

${ }^{3}$ Department of Pharmacology, Medical University of Silesia, Katowice, Poland.

${ }^{4}$ To whom correspondence should be addressed at Medical Research Center, Department of Cellular Signaling, Polish Academy of Sciences, 5 Pawińskiego St., 02-106, Warsaw, Poland; e-mail: mchalim@yahoo.com.
} 


\section{INTRODUCTION}

Phosphatidylinositol (PI) transfer protein (PI-TP) is a small ubiquitously expressed and abundant protein that transfers PI and phosphatidylcholine (PC) between membranes (Wirtz, 1991, 1997; Geijtenbeerk et al., 1994). Recent studies have shown that the cellular functions of PI-TP are not only connected with phospholipid transfer per se from its site of synthesis in the endoplasmic reticulum to the other membranes but also with other important cell functions as vesicle transport, dynamics of cytoskeleton proteins, and PI metabolism (Thomas et al., 1993b; Liscovitch and Cantley, 1995; Monaco et al., 1998; Snoek et al., 1999). PITP is an essential for agonist stimulated synthesis of polyphosphoinositide (Thomas et al., 1993b; Kauffmann-Zeh et al., 1995; Kearns et al., 1998). The high affinity of PI-TP for PIP and PIP $_{2}$ impose that these lipids remain bound to PI-TP after their formation. The PI-TP may also deliver these lipids as a substrates for phospholipase C (PLC) and phospholipase $\mathrm{A}_{2}\left(\mathrm{PLA}_{2}\right)$ (Thomas et al., 1993b; Kauffmann-Zeh et al., 1995; Snoek et al., 1999). A remarkable evidence indicates that membrane traffic events are connected with the activity of PI3'-kinase and with the formation of different class of lipids as phosphatidylinositol (3) phosphate PI(3)P, PI(3,4) $\mathrm{P}_{2}$, and $\mathrm{PI}(3,4) \mathrm{P}_{3}$ (Kular et al., 1997; Panaretou et al., 1997). These lipids are not substrates for PLC but they are very active intracellular messenger molecules.

Polyphosphoinositide containing phosphate in D3 position influences the proteins that regulate vesicle formation and perhaps also their docking and fusion. Hay (1995) has suggested that PI-TPs promote assembly of the actin by cytoskeletal PIP $_{2}$ -binding proteins.

One of the major factors, which can influence the membrane fluidity is phospholipid composition of membrane. Oxidative stress increases lipid peroxidation and also decreases the membrane fluidity (Yehuda et al., 2002). Diminishing of membrane fluidity was observed with aging (Joseph et al., 1998). Previous studies indicate that phosphoinositide metabolism decreases in aged brain and in PD (Bothmer et al., 1992; Klerenyi et al., 1998; Zambrzycka, 2004). It was shown that total polyunsaturated fatty acids (PUFA) level was decreased in the aged brain and may contribute to cell damage by increasing PUFA oxidation and the production of reactive oxygen species (ROS) (Kukreja et al., 1986).

According to the free radicals hypothesis of aging the generation and accumulation of reactive oxygen species result in oxidative damage molecules, which is coupled with insufficient antioxidant defense mechanism (Harman, 1992; Ames

\footnotetext{
Abbreviations used: AMPA, ionotropic $\alpha$-amino-3-hydroxy-5-methyl-4-isoxazole; DMSO, dimethyl sulfoxide; DAT, dopamine transporter; DTT, dithiothreitol; EDTA, ethylenediaminetetraacetic; ECL, enhanced chemiluminescence; FBS, fetal bovine serum; HS, horse serum; mGlu, metabotropic glutamate (mGlu); $\mathrm{MPP}^{+}$, 1-methyl-4-phenyl-pyridine cation; MPTP, 1-methyl-4-phenyl-1,2,3,6tetrahydropyridine; MTT, 3-[4,5-dimethylthiazol-2]-2,5 diphenyl tetrazolium bromide; PD, Parkinson disease; PC12 cells, pheochromocytoma cell line; PBS, phosphate saline buffer; PC, phosphatidylcholine; PI, Phosphatidylinositol; PI-TP, phosphatidylinositol transfer proteins; PLA 2 , phospholipase $\mathrm{A}_{2}$; PLC, phospholipase C; PUFA, polyunsaturated fatty acids; ROS, reactive oxygen species; TBS, Tris-buffered saline; $\mathrm{TH}$, tyrosine hydroxylase.
} 
et al., 1993). Free radicals may also disturb phosphoinositides metabolism, transport, and signaling. It was shown previously by Hamilton et al. (1997) that the vibrator mutation caused neurodegeneration-induced significant reduction of PI-TP mRNA and protein level. Till now little is known about the PI-TPs in brain aging and Parkinson disease.

The aim of this study was to investigate expression of PI-TP $\alpha$ and $\beta$ in the brain during aging and in animal's model of Parkinson disease (PD) induced by 1-methyl4-phenyl-1,2,3,6-tetrahydropyridine (MPTP). Moreover, using PC 12 cells in culture we have investigated the effect of 1-methyl-4-phenyl-pyridine cation ( $\left.\mathrm{MPP}^{+}\right)$on PI$\mathrm{TP}_{\alpha}$ and $\beta$ expression.

\section{MATERIAL AND METHODS}

\section{Materials}

Rabbit polyclonal anti-TH antibody (Biocom International, Temecula, CA, USA), rabbit polyclonal anti- $\beta$-actin antibody, goat anti-rabbit IgG conjugated with horseradish peroxidase (AR-HRP), and goat anti-rabbit conjugated with AP antibody were purchased from Sigma (St. Louis, MO, USA). Nitrocellulose membrane was obtained from Bio-Rad (Wien, Austria). ECL kit was obtained from Amersham Pharmacia Biotech (Piscataway, NJ, USA). Protease inhibitors were from Boehringer-Mannheim (Mannheim, Germany). 1-Methyl-4-phenyl-1,2,3,6tetrahydropyridine (MPTP), and the remaining reagents were purchased from Sigma (St. Louis, MO, USA).

\section{Animals}

4, 18, and 36 months old male Wistar rats (200-250 g) and 8-week-old C57/bl mice (20-25 g) were supplied from the Animal Breeding House of Medical Research Center, Polish Academy of Sciences (Warsaw, Poland). Animals were housed in a temperature-controlled room under a 12-h light/12-h dark cycle with free access to food and water.

\section{MPTP Treatment}

Mice were housed in a temperature-controlled room under a 12-h light/12-h dark cycle with free access to food and water. On the day of the experiment, mice C57/BL received intraperitioneally (i.p.) three injections of MPTP in saline at $2 \mathrm{~h}$ intervals in a total dose $40 \mathrm{mg} / \mathrm{kg}$. Control mice obtained saline only. Mice were sacrificed at 3, 7, and 14 days after MPTP treatment. Different parts of brain as striatum, midbrain, hippocampus, and brain cortex were quickly dissected on an ice-cold glass Petri dish. Samples were immediately frozen in liquid nitrogen and stored at $-70^{\circ} \mathrm{C}$ till analyzed. 


\section{PC12 Cell Culture}

Pheochromocytoma cells line (PC 12 cells) were cultured in $75 \mathrm{~cm}^{2}$ flasks in DMEM supplemented with 10\%-heat-inactivated fetal bovine serum (FBS), 5\% heat-inactivated horse serum (HS), $1 \%$ penicillin/streptomycin $(100 \mathrm{U} / \mathrm{mL}), 2 \mathrm{mM}$ glutamine. Cells were maintained at $37^{\circ} \mathrm{C}$ in a humidified atmosphere of $95 \%$ air and $5 \% \mathrm{CO}_{2}$. Cells were subcultured about once a week. For experiments, confluent cells were subcultured into polyethylenimine-coated $60 \mathrm{~mm}^{2}$ dishes or 24-well plates. Cells were used for experiments 1 day after plated in $24-w e l l$ plate or $75-90 \%$ confluence for determination of PI-TP protein level. Prior to treatment, cells were replenished with DMEM medium containing 2\% FBS, 1\% penicillin/streptomycin (100 U/mL), 2 mM glutamine.

\section{PC12 Cells Treatment}

PC12 cells were treated with $\mathrm{MPP}^{+}(50-300 \mu \mathrm{M}), \mathrm{H}_{2} \mathrm{O}_{2}(500 \mu \mathrm{M})$, menodione $(100 \mu \mathrm{M})$ or NO donor, sodium nitroprusside $(500 \mu \mathrm{M})$ for $24 \mathrm{~h}$ at $37^{\circ} \mathrm{C}$. Then after washing with cold phosphate saline buffer (PBS), cells were lysed in boiling buffer containing $10 \mathrm{mM}$ Tris-HCl pH 7.4, 1\% SDS and protease inhibitors (1 tab/10 mL buffer, Boehringer-Mannheim GmbH, Germany). After sonification, the protein content was determined by the Lowry method (Lowry et al., 1951).

\section{Preparation of Homogenate}

The rats were sacrificed and brain hemispheres or the other parts of brain were quickly dissected on an ice-cold glass Petri dish. The brain cortex, hippocampus, striatum, and cerebellum were homogenized in $10 \mathrm{mM}$ Tris- $\mathrm{HCl}$ buffer $\mathrm{pH} 7.4$ containing $0.25 \mathrm{M}$ sucrose, $1 \mathrm{mM}$ EDTA and protease inhibitors $(1 \mathrm{tab} / 10 \mathrm{~mL}$ buffer, Boehringer-Manheim GmbH, Germany) in a Dounce homogenizer by 14 strokes. The protein content of homogenate was determined by the Lowry method (Lowry et al., 1951).

\section{Gel Electrophoresis and Western Blotting for PI-TP and Tyrosine Hydroxylase (TH)}

Homogenate aliquots (40 $\mu \mathrm{g}$ protein) and an aliquot of purification PI-TP protein $(2 \mu \mathrm{g} / \mathrm{mL}$, positive control) were mixed with an equal volume of sample buffer (62.5 mM Tris-HCl pH 6.8, 2\% SDS, $100 \mathrm{mM} \mathrm{DTT,} 10 \%$ glycerol and $0.025 \%$ bromophenol blue; Laemmli, 1970). The samples were boiled for $5 \mathrm{~min}$ at $95^{\circ} \mathrm{C}$. The proteins were analyzed by electrophoresis on $10 \%$ polyacrylamide gel SDSPAGE (Laemmli, 1970). Then proteins were electrophoretically transferred from the SDS polyacrylamide gel at $1 \mathrm{~mA} / \mathrm{cm}^{2}$ for $75 \mathrm{~min}$ at room temperature to nitrocellulose membranes. The membrane was blocked in 5\% Milk Powder (nonfat dry-milk) in Tris-buffered saline (TBS) containing $0.05 \%$ Tween 20 (TBS-T) for $1 \mathrm{~h}$ at $37^{\circ} \mathrm{C}$. Then the blot was incubated with anti-PI-TP $\alpha \beta$ antibody (raised aganist synthetic peptides, diluted $1: 100)$ in TBS-T containing $0.2 \%(\mathrm{w} / \mathrm{v})$ nonfat milk) or 
anti-TH antibody (diluted 1:1000 in TBS-T), anti- $\beta$-actin (diluted 1:400 in TBS-T) overnight at room temperature. The PI-TP antibody complex was identified with goat anti-rabbit IgG conjugated with alkaline phosphatase (GAR-AP, 1:5000 diluted in TBS-T containing $0.2 \% \mathrm{w} / \mathrm{v}$ nonfat milk). The TH and $\beta$-actin antibodies complex were identified with goat anti-rabbit IgG conjugate with horseradish peroxidase (GAR-HR, diluted 1:8000). The GAR-AP was visualized with 5-bromo4-chloro-3-indoylphosphate $p$-toluidine salt and $p$-nitro blue tetrazolium chloride (BCIP/NBT) as color development substrate for alkaline phosphatase. The GARHR was visualized with ECL kit and Hyperfilm-Kodak (Sigma, MO, USA). The optical densities of the PI-TP and TH bands on the immunoblot were quantified using a NucleoVision apparatus and the GelExpert 4.0 software.

\section{Assessment of Cell Viability}

Cell viability was determined by MTT (3-[4,5-dimethylthiazol-2]-2,5 diphenyl tetrazolium bromide) conversion. This assay takes advantage of the conversion of the yellow MTT to purple formazan crystals by mitochondrial succinate dehydrogenase in viable cells.

The cells were treated with $\mathrm{MPP}^{+}$or $\mathrm{H}_{2} \mathrm{O}_{2}$, menadione, NO donors for $24 \mathrm{~h}$ as described earlier and in legend to figures. After the cell treatment, the culture medium was removed and replaced with MTT solution at the final concentration of $0.25 \mathrm{mg} / \mathrm{mL}$ in DMEM medium and incubated for $2 \mathrm{~h}$ to allow the conversion of MTT into formazan crystals in a $5 \% \mathrm{CO}_{2}$ humidified chamber. Then the MTT solution was removed from cells and cells were lysed with dimethyl sulfoxide (DMSO) and absorbance was read at $595 \mathrm{~nm}$ on a 96-well plate using ELISA BioRad Microplate Reader (Wien, Austria). The results were expressed as percentage of control.

\section{Statistical Analysis}

The results were expressed as mean \pm SEM. Differences among means were analyzed using one-way ANOVA followed by Newman-Keuls posthoc test when appropriate. $p<0.05$ was considered significant.

\section{RESULTS}

The level of PI-TP $\alpha$ and $\beta$ and TH were determinated using immunochemistry method (Western Blot analysis). Purified PI-TP protein level was used as a standard for calculation of amount of PI-TP in samples. Densitometric analysis indicated that PI-TP $\alpha$ and $\beta$ level is similar in all investigated brain parts: the hippocampus, brain cortex, striatum, and cerebellum of adult rats (Fig. 1). PI-TP $\mathrm{TP}_{\alpha}$ and $\beta$ protein level decreased by $20 \%$ in aged brain of 36 months old rats compared to the adults ( 4 months old rats, control). PI-TP protein level did not change in brain of 18 months old rats (Fig. 2). 


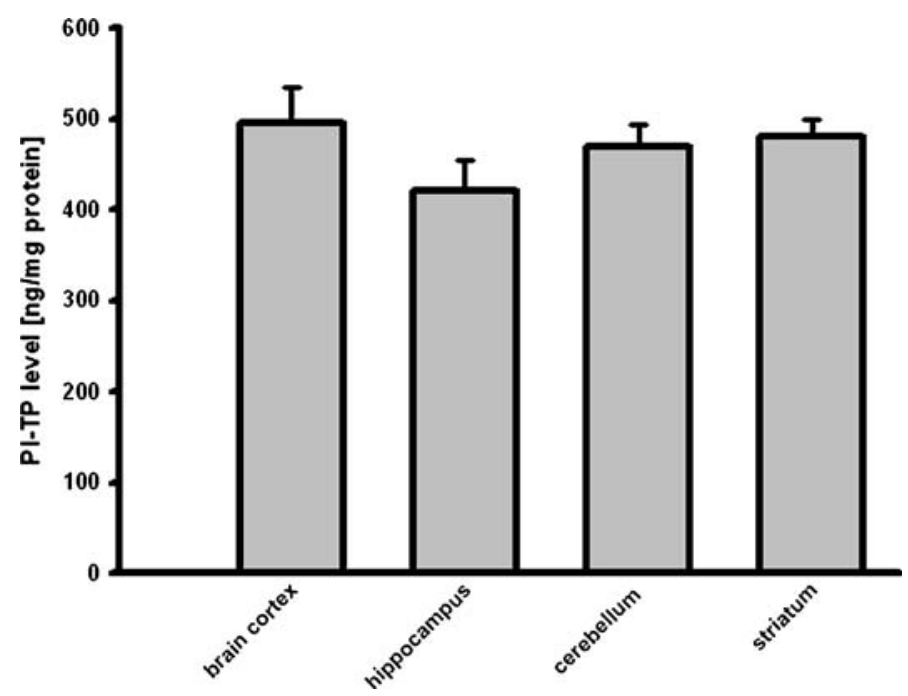

Fig. 1. PI-TP level in the brain cortex, hippocampus, striatum, and cerebellum. Results are the mean values \pm SEM of seven separate experiments and are expressed as $\mathrm{ng} / \mathrm{mg}$ protein.

In animal's model of PD, the PI-TP ${ }_{\alpha}$ and $\beta$ level was significantly lower in striatum 3, 7, and 14 days after MPTP injection and decreased by $85,69,64 \%$, respectively compared to the control value (nontreated mice) (Fig. 3). MPTP administration caused about 40,45 , and $55 \%$ decrease in the dopaminergic fibers in striatum at 3, 7, 14 days after the treatment, respectively (Chalimoniuk et al., 2004a).

MPTP is metabolized by monoamine oxidase $\mathrm{B}$ (MAO-B) to $\mathrm{MPP}^{+}$, which is transported into dopaminergic neurons by dopamine transporter (DAT) and induced many biochemical changes. In vitro studies indicated that dose-dependent $\mathrm{MPP}^{+}$altered PI-TP ${ }_{\alpha}$ and $\beta$ protein level in PC12 cells (Fig. 4). However, dose- dependent $\mathrm{MPP}^{+}$decreased PC12 cells viability and TH protein level in PC12 cells (Fig. 5). Compounds inducing peroxidation, such as $\mathrm{H}_{2} \mathrm{O}_{2}$, menadione, and $\mathrm{NO}$ donor, which decreased PC12 cells viability of about $80 \%$, caused significant reduction of the PI-TP $\alpha$ and $\beta$ protein concentration in PC12 cells (Fig. 6).

\section{DISCUSSION}

These studies indicated that PI-TP $\alpha$ and $\beta$ protein level decreased significantly in aged brain of 36 months old rats and in striatum of mice in PD model. Our in vitro study indicated that free radicals are involved in significant reduction of $\mathrm{PI}-\mathrm{TP}_{\alpha}$ and $\beta$ protein level and suggested that they may be responsible for $\mathrm{PI}_{-} \mathrm{TP}_{\alpha}$ and $\beta$ alteration in aged brain and in mice model of Parkinson disease. The lower concentration of PI-TP $\alpha$ and $\beta$ in aged brain and in mice model of PD may disturb phosphoinositides signaling and membrane fluidity. 
A.

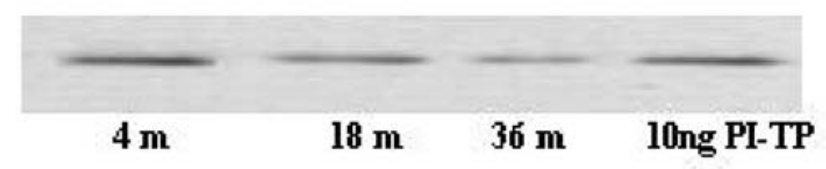

B.

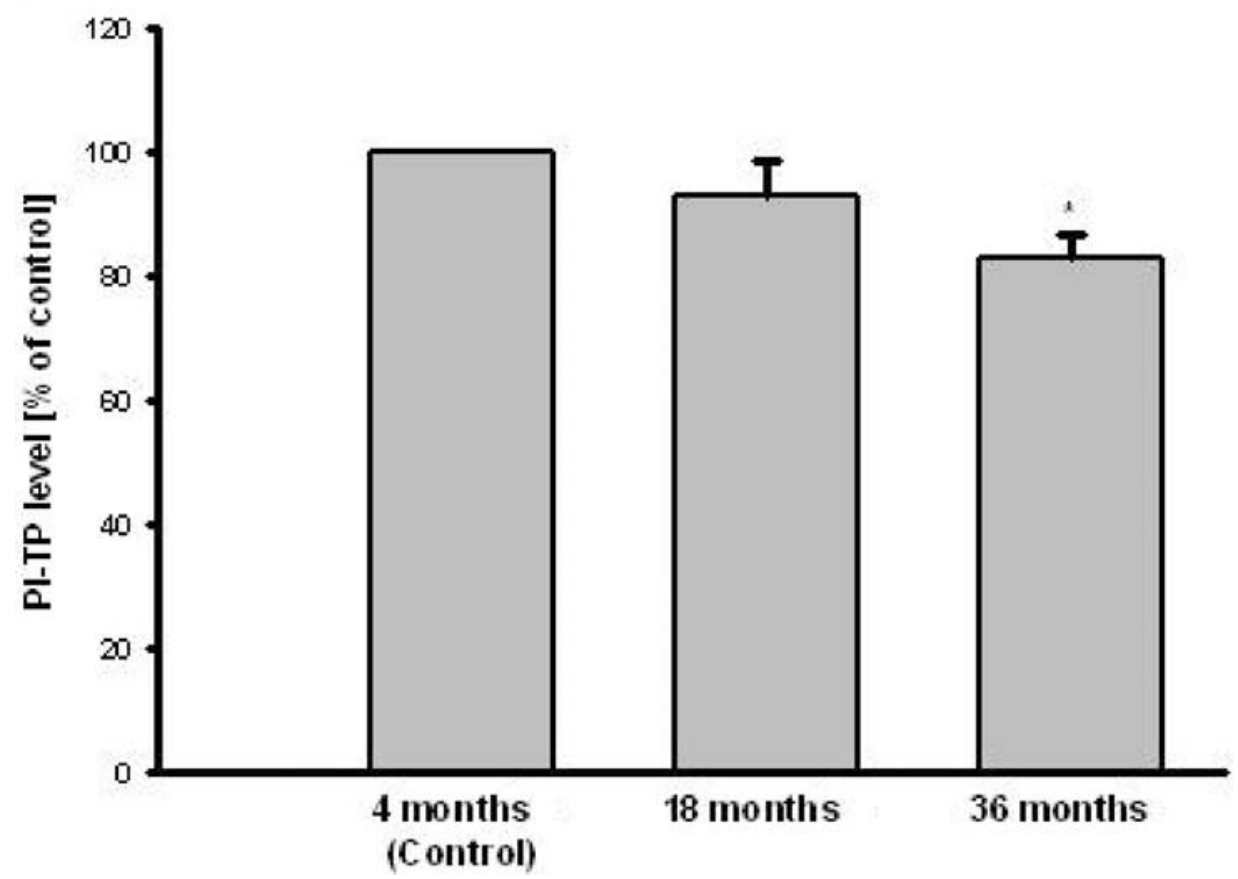

Fig. 2. The effect of aging on PI-TP level in brain rats. (A) Western Blot analysis of PI-TP. The photographic inserts show typical results of Western Blot product analyses. Lanes: $4 \mathrm{~m}$-brain of 4 months old rat (control), 18m-brain of 18 months old rat (old), $36 \mathrm{~m}$-brain of 36 months old rat, PI-TP-10 ng purification of PI-TP protein as positive control. (B) Densitometric analysis results are the mean values \pm SEM of four separate experiments and are expressed as the percentage of the respective control. * $p<0.05$ versus the control (one-way ANOVA followed by the Student-NewmanKeuls test).

Previous studies indicate that phosphoinositide metabolisms decrease in aged brain and in PD (Bothmer et al., 1992; Klerenyi et al., 1998; Tariq et al., 2001; Zambrzycka, 2004). The activation of enzymes, which hydrolyzed phospholipids $\left(\mathrm{PLA}_{2}, \mathrm{PLC}\right)$ and released free arachidonic acid (AA) were enhanced in aged brain and PD (Klerenyi et al., 1998; Tariq et al., 2001). Additionally, it was shown that total polyunsaturated fatty acids level was decreased in the aged brain as a consequence of free radicals dependent oxidation (Yehuda et al., 2002). It is known, that free radicals (oxidative stress) have been implicated in mechanism leading to neuronal cells 
A.

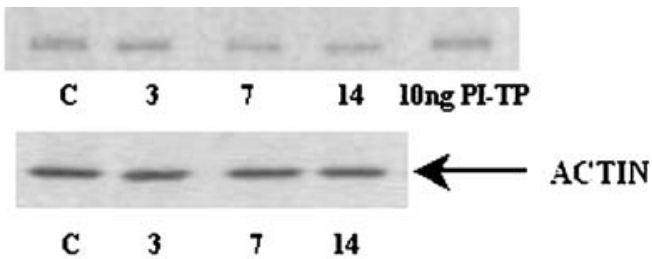

B.

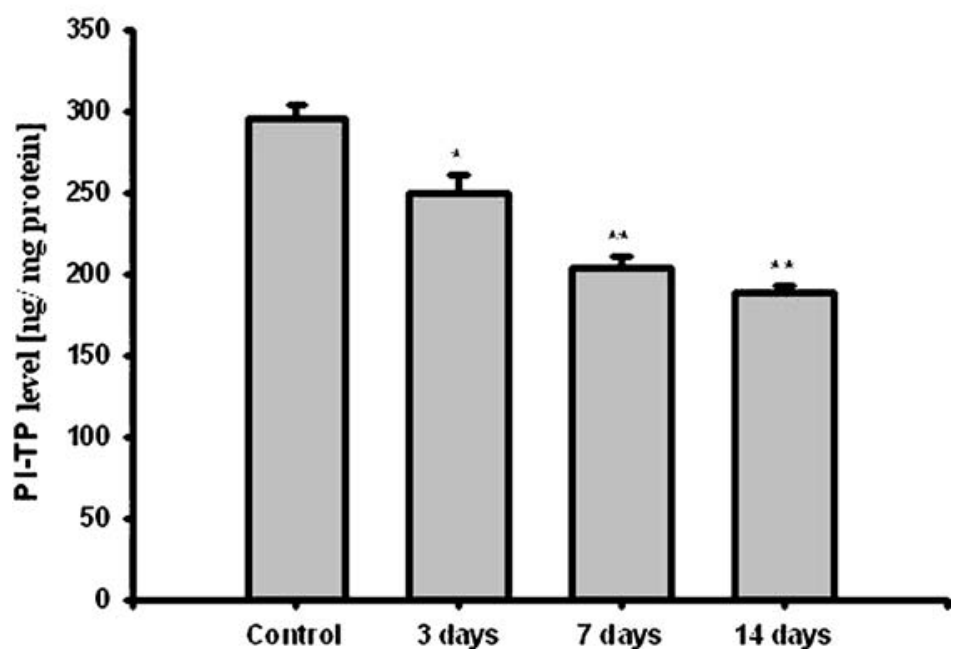

Fig. 3. Effect of MPTP on PI-TP level in striatum at 3, 7, and 14 days after treatment. (A) Western Blot analysis of striatum PITP. The photographic inserts show typical results of Western Blot product analyses. Lanes: C-control, 3-3 days, 7-7 days, and 14-14 days after MPTP injection, PI-TP - 10 ng purification of PI-TP as positive control. (B) PI-TP level in striatum after MPTP treatment. The results are the mean values \pm SEM of five separate experiments and are expressed as the percentage of the respective control. ${ }^{*} p<0.005$, ** $<0.001$ versus the control (one-way ANOVA followed by the StudentNewman-Keuls test).

injury in various pathological states of the brain as Parkinson, Alzheimer diseases (Zhang et al., 2000; Calabrese et al., 2003; Barja, 2004).

Our studies indicated that PI-TP protein level was decreased in aged brain and in striatum of MPTP-induced Parkinsonism. Our in vitro study indicated that MPP ${ }^{+}$ decreased PI-TP and TH protein levels and viability in PC12 cells. These results suggest that transfer of PI and other lipids from the site of synthesis to the intracellular and plasma membranes is diminished. Simultaneously increased phospholipids hydrolysis by $\mathrm{PLA}_{2}$ in the brain aging and PD was observed. In consequence the phospholipids composition of membrane may undergo modification in aged and PD brains. Phospholipids composition of membrane influence membrane fluidity and phospholipids signaling. A lowering of membrane fluidity was observed with aging (Joseph et al., 1998). Yehuda et al. (2002) have shown that oxidative stress, which 
A.
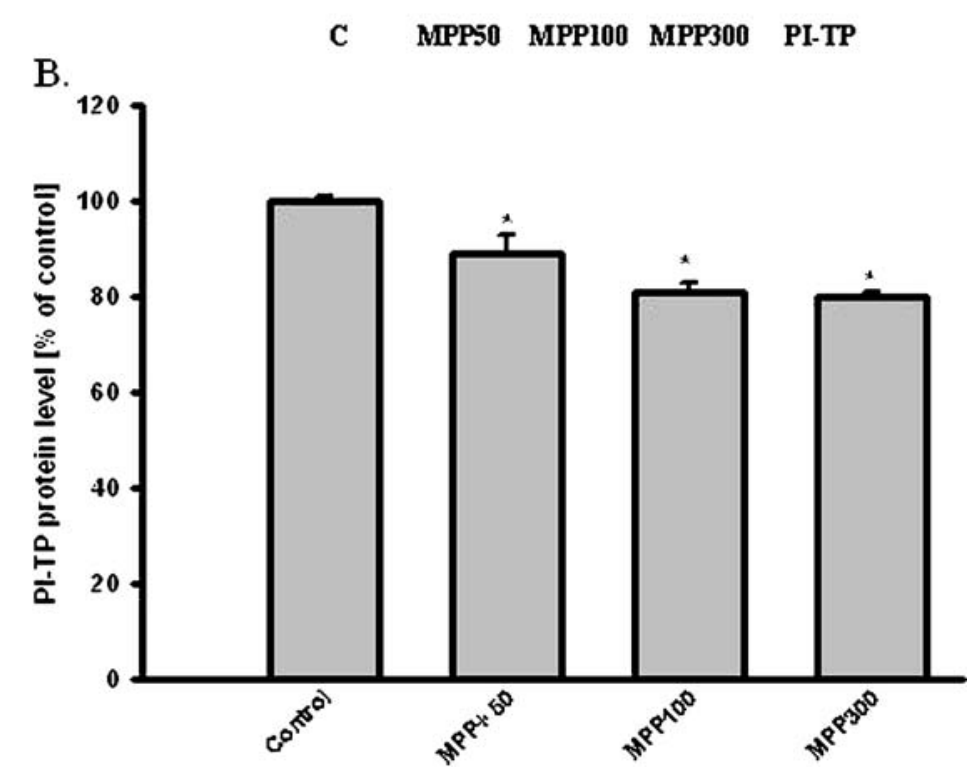

Fig. 4. Effect of MPP + on PI-TP level in PC12 cells. (A) Western Blot analysis of PI-TP immunoreactivity. The photographic inserts show typical results of Western Blot product analyses. Lanes: C-control, MPP50-MPP ${ }^{+} 50 \mu \mathrm{M}$, MPP100-MPP ${ }^{+} 100 \mu \mathrm{M}$, MPP300-MPP $+300 \mu \mathrm{M}$, PI-TP- 10 ng purification of PI-TP as a positive control. (B) Densitometric analysis results are the mean values \pm SEM of four separate experiments and are expressed as the percentage of the respective control. ${ }^{*} p<0.001$ versus the control (one-way ANOVA followed by the Student-Newman-Keuls test).

leads to an increase of free radicals increases lipid peroxidation and decreases the membrane fluidity (Yehuda et al., 2002). Enhanced free AA level by excessive activation of $\mathrm{PLA}_{2}$ induced modification of membrane fluidity (Katsuki and Okuda, 1995), and it may exert several neurotoxic effects (Toborek et al., 1999; Garrido et al., 2001). In addition, arachidonic acid is a very potent messenger involved in synaptic transmission, and in a variety of signal transduction pathways (Katsuki and Okuda, 1995).

Studies performed on patients with PD and on animal model of PD have demonstrated an increase in oxidative stress in substantia nigra including lipid peroxidation, production of free radicals (Dexter et al., 1989; Przedborski et al., 1996; Jenner, 1998; Chalimoniuk et al., 2004b), and decreased glutathione concentration (Sian et al., 1994; Beal, 1995; Beal et al., 1998; Bharath et al., 2002).

Our in vitro study indicated that free radicals induced the decrease of PI-TP protein level in $\mathrm{PC} 12$ treated with peroxidant compounds as $\mathrm{H}_{2} \mathrm{O}_{2}$, menodione, NO 
A.

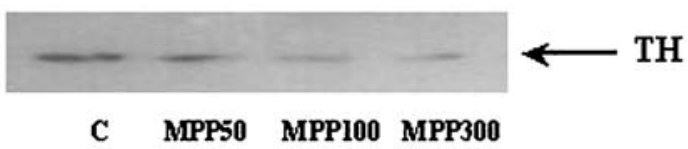

B.

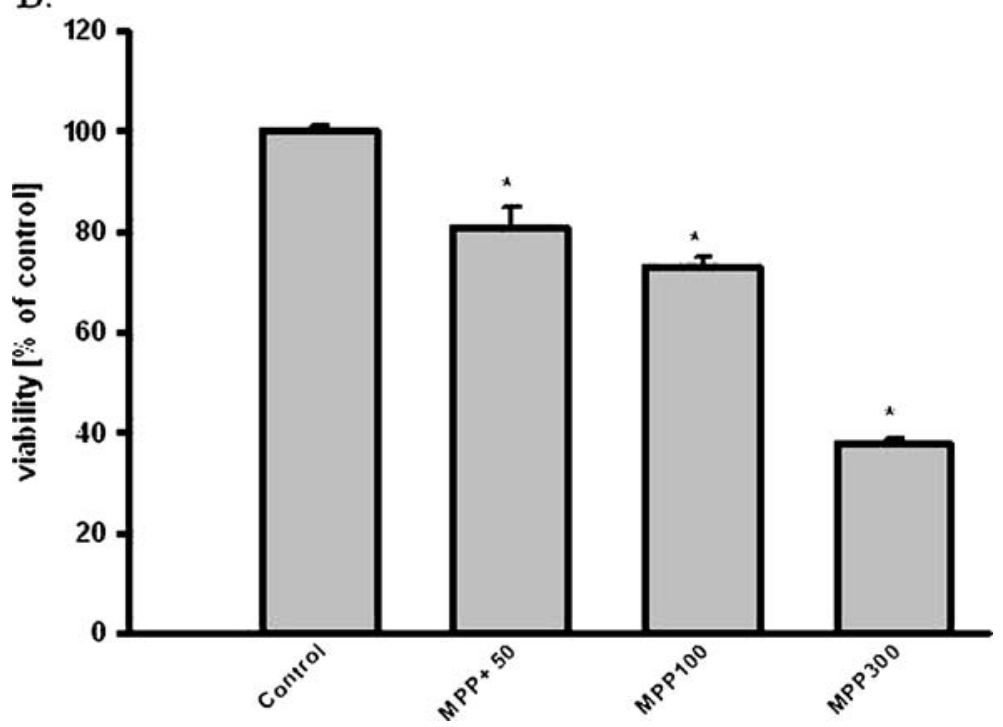

Fig. 5. Effect of $\mathrm{MPP}^{+}$on TH protein level and viability in $\mathrm{PC} 12$ cells. (A) Western Blot analysis of TH protein level. The photographic inserts show typical results of Western Blot product analyses. Lanes: C-control, MPP50- $\mathrm{MPP}^{+}$ $50 \mu \mathrm{M}, \mathrm{MPP} 100-\mathrm{MPP}^{+} 100 \mu \mathrm{M}, \mathrm{MPP} 300-\mathrm{MPP}^{+} 300 \mu \mathrm{M}$. (B) PC12 cells viability results are the mean values \pm SEM of four separate experiments and are expressed as the percentage of the respective control. ${ }^{*} p<0.001$ versus the control (one-way ANOVA followed by the Student-Newman-Keuls test).

donor, and decreased PC12 cells viability. The free radicals may be involved in PI$\mathrm{TP}$ alteration in brain aging and PD.

The role of PI-TP in physiology and pathology of the central nervous system (CNS) is still not clear. These proteins are involved in phospholipids degradation, phospholipids transport, as well as in dynamic cytoskeleton changes and in function of Golgi system (Wirtz, 1991, 1997; Snoek et al., 1999). It seems that the decrease of PI-TP protein level may be one of the important factors that lead to disturbing of phospholipids signaling and also may be involved in neurodegeneration of CNS. Alb et al. $(2002,2003)$ indicated that lack of PI-TP $\alpha$ caused aponecrotic spinocerebrallar disease in PI-TP $\alpha$ knockout mice. The mice lacking PI-TP $\alpha$ die soon after birth (Alb et al., 2002). The vibrator mutation caused an early-onset progressive action tremor, degeneration of brain stem and spinal cord neurons, and juvenile death. PI-TP mRNA and protein level were decreased five times in vibrator mutation (Hamilton et al., 1997). 
A.
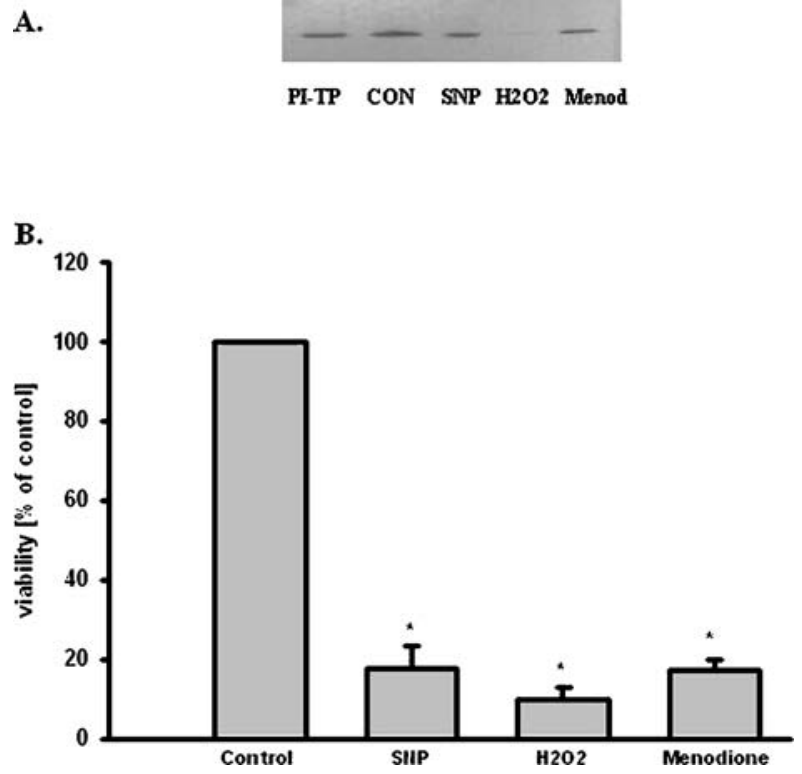

Fig. 6. Effect of prooxidative compounds on PI-TP protein level and PC12 cells viability. (A) Western Blot analysis of PITP protein level. The photographic inserts show typical results of Western Blot product analyses. Lanes: $\mathrm{C}-$ control, SNP-SNP $500 \mu \mathrm{M}, \mathrm{H}_{2} \mathrm{O}_{2}-\mathrm{H}_{2} \mathrm{O}_{2} 500 \mu \mathrm{M}$, Menod-menodione $100 \mu \mathrm{M}$. PITP-10 ng purification of PI-TP as positive control. (B) PC12 cells viability results are the mean values \pm SEM of four separate experiments and are expressed as the percentage of the respective control. ${ }^{*} p<0.001$ versus the control (one-way ANOVA followed by the Student-Newman-Keuls test).

On the other hand, the increase of PI-TP level may prevent neurodegeneration. PI-TP plays a role in delivery PI to PI4-kinase, which synthesize PI 4,5-bisphosphate $\left(\mathrm{PIP}_{2}\right)$, these lipids remain bound to PI-TP, which may also deliver these substance for PLC (Thomas et al., 1993a). The activation of PLC-pathway leads to elevated level of diacylogicerol (DAG). In the next steps DAG activates PKC, which, via phosphorylation initiates MAP kinase cascade. Jiang et al. (2002) showed that MAPK/ERK1/2 signaling was involved in protection of cultured cerebral cortical astrocytes against ischemic injury. It has been shown that ERK2 caused an increase in bcl-2 expression and inhibition cellular apoptosis. The elevated expression of PI$\mathrm{TP} \alpha$ was also observed in astrocytes subjected to ischemia in vitro after treatment with aniracetam (1-anisoyl-2-pyrrolidinone), a modulator of ionotropic $\alpha$-amino-3hydroxy-5-methyl-4-isoxazole (AMPA) and metabotropic glutamate (mGlu) receptors (Gabryel et al., 2005). Aniracetam could affect PI-TP, that activation of these proteins was involved in escalation of MAP kinase cascade and prevented ischemiainduced apoptosis of astrocyte cells (Gabryel et al., 2004, 2005).

In summary, our results suggest that oxidative stress may be responsible for the decrease of $\mathrm{PI}_{-} \mathrm{TP}_{\alpha}$ and $\beta$ level in aged brain and in PD that may disturb 
phosphoinositides transport, metabolism and influence cytoskeleton dynamic and function. In consequence this decrease may lead to neurodegeneration and death of neurons in aged brain and PD.

\section{ACKNOWLEDGMENT}

This work was supported by RSC grant 3P05A13622, and PBZ-MIN001/P05/16.

\section{REFERENCES}

Alb, J. G. Jr., Cortese, J. D., Philips, S. E., Albin, R. L., Nagy, T. R., Hamilton, B. A., and Bankaitis, V. A. (2003). Mice lacking phosphotidylinositol transfer protein-alpha exhibit spinocereberallar degeneration, intestinal and hepatic steatosis, and hypoglycemia. J. Biol. Chem. 29:33501-33518.

Alb, J. G. Jr., Philips, S. E., Rostand, K., Cui, X., Pinxteren, J., Cotlin, L., Manning, T., et al. (2002). Genetic ablation of Phosphatidylinositol transfer protein function in murine embryonic stem cells. Mol. Biol. Cell 13:739-754.

Ames, B. N., Shigenaga, M. K., and Hagen, T. M. (1993). Oxidants antioxidants and the degenerative diseases of aging. Proc. Natl. Acad. Sci. U.S.A. 90:7915-7922.

Barja, G. (2004). Free radicals and aging. Trends Neurosci. 27(10):595-600.

Beal, M. F. (1995). Aging, energy and oxidative stress in neurodegenerative diseases. Ann. Neurol. 38:357-366.

Beal, M. F., Matthews, R. T., Tieleman, A., and Shults, C. W. (1998). Coenzyme Q10 attenuates the 1methyl-4-phenyl-1,2,3,6-tetrahydropyridine (MPTP) induced loss of striatal dopamine and dopaminergic axons in aged mice. Brain Res. 783:109-114.

Bharath, S., Hsu, M., Kaur, D., Rajagopalan, S., and Andersen, J. K. (2002). Glutathione, iron and Parkinson's disease. Biochem. Pharmacol. 64:1037-1048.

Boje, K. M. (2004). Nitric oxide neurotoxicity in neurodegenerative diseases. Front. Biosci. 9:763-776.

Bothmer, J., Mommers, M., Markerink, M., and Jolles, J. (1992). The effect of age on phosphatidylinositol kinase, phosphatidiyliositol phosphate kinase and diacylglycerol kinase activities in rat brain cortex. Growth Dev. Aging 58:67-73.

Calabrese, V., Scapaginini, G., Colombrita, C., Ravagna, A., Pennisi, G., Giuffrida, Stella, A. M., Galli, F., and Butterfield, D. A., (2003). Redox regulation of heat shock protein expression in aging and neurodegenerative disorders associated with oxidative stress: A nutritional approach. Amino Acids 25:435-444.

Chalimoniuk, M., Langfort, J., Lukacova, N., and Marsala, J. (2004a). Upregulation of guanylyl cyclase expression and activity in striatum of MTPT-induced Parkinsonism in mice. Biochem. Biophys. Res. Commun. 324:118-126.

Chalimoniuk, M., Stepien, A., and Strosznajder, J. B. (2004b). Pergolide mesilate, dopaminergic receptor agonist, applied with L-DOPA enhances serum antioxidant enzymes activity in Parkinson Disease. Clin. Neuropharmacol. 27:223-229.

Dexter, D. T., Carter, C. J., and Wells, F. R. (1989). Basal lipid peroxidation in substantia nigra is increased in Parkinson's disease. J. Neurochem. 52:381-389.

Gabryel, B., Chalimoniuk, M., Małecki, A., and Strosznajder, J. (2005). Effect of aniracetam on phosphatidylinositol transfer protein alpha in cytosolic and plasma membrane fractions of astrocytes subjected to simulated ischemia in vitro. Pharmacol. Rep. 57:664-669.

Gabryel, B., Pudełko, A., and Małecki, A. (2004). Erk1/2 and Akt kinases are involved in the protective effect of aniracetam in astrocytes subjected to stimulated ischemia in vitro. Eur. J. Pharmacol. 494:111-120.

Garrido, R., Mattson, M. P., Hennig, B., and Toborek, M. (2001). Nicotine protects against arachidonicacid-induced caspase activation, cytochrome $\mathrm{c}$ release and apoptosis of cultured spinal cord neurons. J. Neurochem. 76:1395-1403.

Geijtenbeek, T. B., de Groot, E., van Baal, J., Brunink, F., Westerman, J., Snoek, G. T., and Wirtz, K. W. (1994). Characterization of mouse phosphatidylinositol transfer protein expressed in Escherichia coli. Biochim. Biophys. Acta 1213:309-318.

Hamilton, B. A., Smith, D. J., Kerrebrock, A. W., Bronson, R. T., van Berkel, V., Daly, M. J., Kruglyak, L., Reeve, M. P., Nemhauser, J. L., Hawkins, T. L., Rubin, E. M., and Lander, E. S. (1997). The 
vibrator mutation causes neurodegeneration via reduced expression of PI-TP alpha: Positional complementation cloning and extragenic suppression. Neuron 18:711-722.

Harman, D. (1992). Role of free radicals in aging and disease. Ann. N.Y. Acad. Sci. 673:126-141

Hay, J. E. (1995). Bone disease after liver transplantation. Liver Transpl. Surg. 1:55-63.

Jenner, P. (1998). Oxidative mechanisms in nigral cell death in Parkinson's disease. Mov. Disord. 13(Suppl. 1):24-34.

Jenner, P., and Olanow, C. W. (1996). Pathological evidence for oxidative stress in Parkinson's disease and related degenerative disorders. In Olanow, C. W., Jenner, P., and Youdim, M. (eds.), Neurodegeneration and Neuroprotection in Parkinson's Disease, London Academic, London, pp. 24-45.

Jiang, Z., Zuang, Y., Chem, X., Lam, P. Y., Yang, H., Xu, Q., and Yu, A. C. H. (2002). Activation of ERK1/2 in astrocytes under ischemia. Biochem. Biophys. Res. Commun. 294:726-733.

Joseph, J. A., Denisova, N. A., Fisher, D., Bickford, P., and Cao, G. (1998). Age-related neurodegeneration and oxidative stress: Putative nutritional intervention. Neurol. Clin. 16:747-755.

Katsuki, H., and Okuda, S. (1995). Arachidonic acid as a neurotoxic and neurotrophic substance. Prog. Neurobiol. 46:607-636.

Kauffmann-Zeh, A., Thomas, G. M., Ball, A., Prosser, S., Cunningham, E., Cockcroft, S., and Hsuan, J. J. (1995). Requirement for phosphatidylinositol transfer protein in epidermal growth factor signalling. Science 268:1188-1190.

Kearns, B. G., Alb, J. G. Jr., and Bankaitis, V. (1998). Phosphatidylinositol transfer proteins: The long and winding road to physiological function. Trends Cell Biol. 8:276-282Author: Please check the page range in Kearns et al. (1998).

Klerenyi, P., Beal, M. F., Ferrante, R. J., Andreassen, O. A., Wermer, M., Chin, M. R., and Bonventre, J. V. (1998). Mice deficient in group IV cytosolic phospholipase A2 are resistant to MPTP neurotoxicity. J. Neurochem. 71:2634-2637.

Kukreja, R. C., Kontos, H. A., Hess, M. L., and Ellis, E. F., (1986). PGH synthase and lipooxygenase generate superoxide in the presence of NADH or NADPH. Circ. Res. 59:612-619.

Kular, G., Loubtchenkov, M., Swigart, P., Whatmore, J., Ball, A., Cockcroft, S., and Wetzker, R. (1997). Co-operation of phosphatidylinositol transfer protein with phosphoinositide 3-kinase gamma in the formylmethionyl-leucylphenylalanine-dependent production of phosphatidylinositol 3,4,5trisphosphate in human neutrophils. Biochem. J. 325:299-301.

Laemmli, U. K. (1970). Cleavage of structural proteins during the assembly of the head of bacteriophage T4. Nature 227:680-685

Liscovitch, M., and Cantley, L. C. (1995). Signal transduction and membrane traffic: The PITP/phosphoinositide connection. Cell 81:659-662

Lowry, O. H., Rosebrough, N. J., Farr, A. L., and Randell, R. J. (1951). Protein measurement with Folin phenol reagent. J. Biol. Chem. 193:265-275.

Monaco, M. E., Alexander, R. J., Snoek, G. T., Moldover, N. H., Wirtz, K. W., and Walden, P. D. (1998). Evidence that mammalian phosphatidylinositol transfer protein regulates phosphatidylcholine metabolism. Biochem. J. 335:175-179

Panaretou, C., Domin, J., Cockcroft, S., and Waterfield, M. D., (1997). Characterization of p150, an adaptor protein for the human phosphatidylinositol (PtdIns) 3-kinase. Substrate presentation by phosphatidylinositol transfer protein to the p150.Ptdins 3-kinase complex. J. Biol. Chem. 272:24772485.

Przedborski, S., Jackson-Lewis, V., Yokoyama, R., Shibata, T., Dawson, V. L., and Dawson, T. M. (1996). Role of nitric oxide in 1-methyl-4-phenyl-1,2,3,6-tetrapyridine (MPTP)-induced dopamninergic neurotoxicity. J. Neurosci. 12:1658-1667.

Sian, J., Dexter, D. T., and Lees, A. J. (1994). Alterations in glutathione levels in Parkinson's disease and other neurodegenerative disorders affecting basal ganglia. Ann. Neurol. 36:348355.

Snoek, G. T., Berrie, C. P., Geijtenbeek, T. B., van der Helm, H. A., Cadee, J. A., Iurisci, C., Corda, D., and Wirtz, K. W. (1999). Overexpression of phosphatidylinositol transfer protein alpha in NIH3T3 cells activates a phospholipase A. J. Biol. Chem. 274:35393-35399.

Tariq, M., Khan, H. A., Moutaery, K. A., and Deeb, S. A. (2001). Protective effect of quinacrine on striatal dopamine levels in 6-OHDA and MPTP models of Parkinsonism in rodents. Brain Res. Bull. 54:77-82.

Thomas, G. M. H., Cunningham, E., Fensome, A., Ball, A., Totty, N. F., and Cockcroft, S. (1993a). An essential role for Phosphatidylinositol transfer protein in phospholipase C-mmediated inositol lipid signaling. Cell 74:919-928.

Thomas, J. B., Clark, S. M., and Gioia, D. A. (1993b). Strategic sensemaking and organizational performance: Linkages among scanning, interpretation, action, and outcomes. Acad. Manage. J. 36:239270 
Toborek, M., Malecki, A., Garrido, R., Mattson, M. P., Hennig, B., and Young, B. (1999). Arachidonic acid-induced oxidative injury to cultured spinal cord neurons. J. Neurochem. 73:684-692

Wirtz, K. W. (1991). Phospholipid transfer proteins. Annu. Rev. Biochem. 60:73-99.

Wirtz, K. W. (1997). Phospholipid transfer proteins revisited. Biochem. J. 324:353-360.

Yehuda, S., Rabinovicz, S., Carasso, R. L., and Mostofsky, D. I. (2002). The role of polyunsaturated fatty acids in restoring the aging neuronal membrane. Neurobiol. Aging 23:843-853.

Zambrzycka, A., (2004). Aging decreases phosphatidylinositol-4,5-bis-phosphate level but has no effect on activities of phosphoinositide kinases. Pol. J. Pharmacol. 56:651-654.

Zhang, Y., Dawson, V. L., and Dawson, T. M. (2000). Oxidative stress and genetics in the pathogenesis of Parkinson's disease. Neurobiol. Dis. 7:240-250. 